City University of New York (CUNY)

CUNY Academic Works

2012

\title{
Responding to Secondary Traumatic Stress: A Pilot Study of Torture Treatment Programs in the United States
}

Adeyinka M. Akinsulure-Smith

CUNY City College

Eva Keatley

New York University School of Medicine

Andrew Rasmussen

New York University School of Medicine

\section{How does access to this work benefit you? Let us know!}

More information about this work at: https://academicworks.cuny.edu/cc_pubs/389

Discover additional works at: https://academicworks.cuny.edu

This work is made publicly available by the City University of New York (CUNY).

Contact: AcademicWorks@cuny.edu 


\title{
BRIEF REPORT
}

\section{Responding to Secondary Traumatic Stress: A Pilot Study of Torture Treatment Programs in the United States}

\author{
Adeyinka M. Akinsulure-Smith, ${ }^{1}$ Eva Keatley, ${ }^{2}$ and Andrew Rasmussen ${ }^{2}$ \\ ${ }^{1}$ Department of Psychology, the City College of New York, City University of New York; New York University School of \\ Medicine; and the Bellevue/NYU Program for Survivors of Torture, New York, New York, USA \\ ${ }^{2}$ New York University School of Medicine and the Bellevue/NYU Program for Survivors of Torture, New York, New York, USA
}

\begin{abstract}
Providers who care for torture survivors may be at risk for secondary traumatic stress, yet there has been little documentation of the effects of repeated exposure to traumatic issues on their emotional health or exploration of the support systems and resources available to address their emotional needs. This study assessed the secondary stress experiences of service providers $(N=43)$ within the National Consortium of Torture Treatment Programs in the United States and examined the supports offered by their organizations. The study found a significant correlation between rates of anxiety and depression among providers, $r(34)=.49, p=.003$. Although these participants reported that their work with survivors of torture was stressful, $91 \%$ indicated that their organizations offered a variety of stress-reduction activities. Overall, participants reported that their own personal activities were the most-effective stress reducers. The results are discussed in light of challenges that professionals who work with this population face and the effectiveness of support systems available to support their work.
\end{abstract}

Survivors of torture face multiple challenges related to their past traumatic experiences, as well as medical, psychological, social, and legal issues related to immigration (Blanch, 2008; Eisenman, Gelberg, Liu, \& Shapiro, 2003; Fabri, 2001; Silove, 1999). Mental health concerns include not only posttraumatic stress disorder (PTSD), but depression, anxiety, and somatization disorders (Gerrity, Keane, \& Tuma, 2001; Piwowarczyk, Moreno \& Grodin, 2000; Wenzel, Griengl, Stompe, Mirzaei, \& Kieffer, 2000). Since 1982, nearly 200 specialized torture treatment rehabilitation centers have been established worldwide to care for torture survivors (International Rehabilitation Council for Torture Victims [IRCT], 2003). Approximately 400,000 such individuals are currently living in the United States (Piwowarczyk et al., 2000). The National Consortium of Torture Treatment Programs (NCTTP) is made up of approximately 30 specialized treatment programs for torture survivors spread

This research was supported by a Professional Staff Congress-City University of New York (PSC-CUNY) Grant and the Faculty Fellowship Publication Program, City University of New York (FFPP-CUNY) awarded to Adeyinka M. Akinsulure-Smith.

Correspondence concerning this article should be addressed to Adeyinka M. Akinsulure-Smith, Department of Psychology, the City College of New York, New York, NY 10031. E-mail: aakinsulure-smith@ccny.cuny.edu

Copyright (C) 2012 International Society for Traumatic Stress Studies. View this article online at wileyonlinelibrary.com

DOI: $10.1002 /$ jts. 21684 throughout 15 states (Blanch, 2008). Psychological services across treatment centers are best described as theoretically eclectic, with most programs providing supportive psychotherapy in conjunction with pharmacological management (Blanch, 2008; Fabri, 2001).

Although there is a growing body of literature describing how to care for torture survivors (Fabri, 2001; Hanscom, 2001; Pope \& Garcia-Peltoniemi, 1991), little research has been conducted to understand the impact of this work on those who provide these services. As part of their mission to care for torture survivors, many NCTTP staff members must listen to horrific events while providing physical and mental health services; therefore, it is possible that they suffer from secondary traumatic stress (STS; Jenkins \& Baird, 2002). STS describes the adverse reactions people can have while trying to help trauma survivors. STS symptoms include reactions to trauma, and are nearly identical to the PTSD symptoms of intrusion, emotional numbing and avoidance, and hyperarousal (Jenkins \& Baird, 2002). Assessing STS is similar to assessing PTSD.

Although a number of organizations within the NCTTP claim to provide psychosocial support to their staff, there has been no evaluation of these services or the symptoms they target. The current study sought to address this gap in the literature by assessing STS among NCTTP service providers and by examining the types of systems and resources that have been put in place to support their emotional needs. 


\section{Method}

\section{Participants}

In the fall of 2008, 120 service providers within the NCTTP were sent survey packets; $43(35.8 \%)$ completed and returned surveys. Respondents were $62.8 \%$ female $(n=27)$ and ranged in age from 25 to 58 years $(M=40.95, S D=9.06)$. Over half were married or were with a long-term partner $(n=26$, $60.5 \%)$. Half had children $(n=22,51.2 \%)$ and $30(69.8 \%)$ were White, 4 (9.3\%) were Black, 2 (4.7\%) Latino, $2(4.7 \%)$ East Asian, 1 (2.3\%) South Asian, and 4 (9.3\%) were of another racial ethnic group. The highest level of education varied, with $15(34.9 \%)$ having a doctoral degree, 18 (41.9\%) a master's degree, 5 (11.6\%) an undergraduate degree, and 5 (11.6\%) an associate degree.

Procedures were approved by the Institutional Review Board of the City College of New York and participants gave written informed consent. Survey packets were mailed to $120 \mathrm{ser}-$ vice providers listed on the websites of NCTTP treatment centers. Included in the survey packets were self-addressed envelopes to ensure return of all completed packets; 4 weeks later, follow-up postcard reminders were sent. In an effort to increase responses, approximately 8 months later the procedure was repeated.

\section{Measures}

Demographic data included age, race, ethnicity, gender, marital status, level of education, place and length of employment, and job description. Also measured were type of work stressors, available support services, and coping strategies for work stressors.

The Life Events Checklist (LEC; Blake, Weathers, Nagy, Kaloupek, Charney, \& Keane, 1995) is a self-report measure of exposure to traumatic events in a respondent's lifetime. Respondents are asked to rate their level of exposure to 17 traumatic events on a 5-point scale. In the current study, respondents were asked to report the number of times each exposure occurred and if the occurrence was work related.

Secondary traumatic stress was measured using the PTSD Checklist-Civilian Version (PCL-C; Weathers, Litz, Herman, Huska, \& Keane, 1993), a self-report measure that lists the 17 symptoms of PTSD according to the Diagnostic and Statistical Manual of Mental Disorders (4th ed., DSM-IV; American Psychiatric Association, 1994). Depression was measured using the Center for Epidemiologic Studies Depression Scale (CESD; Radloff, 1977), a 20 item self-report instrument. Cronbach's $\alpha$ for the 17-item PCL-C and 20-item CES-D were .88 and .74, respectively. Both instruments have been validated on a wide range of populations.

\section{Data Analysis}

Of the 43 returned packets, 41 (95\%) had complete PCL-C scores and $36(84 \%)$ had complete CES-D scores. Frequen-
Table 1

Frequencies of Experiencing, Witnessing, or Learning About Traumatic Events

\begin{tabular}{|c|c|c|c|c|}
\hline \multirow[b]{2}{*}{ Event } & \multicolumn{2}{|c|}{ Overall } & \multicolumn{2}{|c|}{ Work-relatec } \\
\hline & $n$ & $\%$ & $n$ & $\%$ \\
\hline Natural disaster & 21 & 48.8 & 7 & 16.3 \\
\hline Fire or explosion & 9 & 79.1 & 7 & 16.3 \\
\hline Transportation accident & 11 & 25.6 & 4 & 9.3 \\
\hline Serious work or home accident & 8 & 18.6 & 2 & 4.7 \\
\hline Exposure to toxic substance & 4 & 9.3 & 1 & 2.3 \\
\hline Physical assault & 11 & 25.6 & 19 & 44.2 \\
\hline Assault with a weapon & 14 & 32.6 & 19 & 44.2 \\
\hline Sexual assault & 14 & 32.6 & 17 & 39.5 \\
\hline $\begin{array}{l}\text { Other unwanted sexual } \\
\text { experience }\end{array}$ & 9 & 20.9 & 13 & 30.2 \\
\hline $\begin{array}{l}\text { Combat or exposure to a war } \\
\text { zone }\end{array}$ & 14 & 32.6 & 18 & 41.9 \\
\hline Captivity & 13 & 30.2 & 16 & 37.2 \\
\hline $\begin{array}{l}\text { Life-threatening illness or } \\
\text { injury }\end{array}$ & 17 & 39.5 & 16 & 37.2 \\
\hline Severe human suffering & 12 & 27.9 & 18 & 41.9 \\
\hline Sudden, violent death & 9 & 20.9 & 13 & 30.2 \\
\hline Sudden unexpected death & 12 & 27.9 & 9 & 20.9 \\
\hline $\begin{array}{l}\text { Causing serious injury or death } \\
\text { to someone else }\end{array}$ & 9 & 20.9 & 9 & 20.9 \\
\hline
\end{tabular}

Note. $N=42$.

cies and descriptive statistics were calculated for all variables. Association between predictors and outcomes was determined using two-tailed chi-squared and independent sample $t$ tests as appropriate. Factors that were associated with statistically significant univariate results were entered into a multivariate linear regression predicting psychological outcomes.

\section{Results}

\section{Life Events Checklist}

Forty-one participants $(95.3 \%)$ reported having personally experienced, witnessed, or learned about a traumatic event, with the median number of experiences being $14.3(S D=11.1)$. Twenty-four $(55.8 \%)$ reported having experienced at least one work-related traumatic event with the average number of 4.56 $(S D=5.19)$ work-related trauma events. These data are presented in Table 1.

\section{Organizational Support}

Fifteen respondents $(35.7 \%)$ reported that their organization prepares and orients staff working with survivors of torture and refugee trauma very well, $15(35.7 \%)$ reported somewhat adequately, $6(14.3 \%)$ were neutral, and $6(14.3 \%)$ somewhat inadequately. Three-quarters $(n=29,74.4 \%)$ reported that their 
organization provided training programs for staff and about half $(n=22,52.4 \%)$ reported that their organization had good policies and programs in place to support staff in at least most areas, while very few $(n=4,9.5 \%)$ reported their organization did not have good policies and programs in place to support staff. Most participants indicated their organization provided at least one kind of support service for staff $(n=39,90.7 \%)$; the most common support service was the availability of supervisors on an "as needed" basis $(n=33,76.7 \%)$. Three quarters $(n=32,74.4 \%)$ endorsed that they received at least one type of stress management training; just over half ( $n=25,59.1 \%)$ indicated they received technical training to cope with patients in distress.

\section{Stress Management}

Most participants reported they found their work with survivors of torture and refugee trauma to be somewhat stressful $(n=18,42.9 \%)$ or very stressful $(n=9,21.4 \%)$. Common strategies to reduce the stressors experienced included balancing work load by having a variety of tasks $(n=35,81.4 \%)$, supervision/consultation $(n=32,74.4 \%)$, giving and receiving training $(n=28,65.1 \%)$, reducing and distributing client load $(n=24,55.8 \%)$, and finding ways to enhance work space $(n=$ 24, 55.8\%). Most participants found these professional activities to be very helpful $(n=21,48.8 \%)$ or somewhat helpful $(n=$ $20,46.5 \%$ ) in reducing levels of stress. The most common form of organizational activities used by responders to reduce stress was collegial support $(n=38,90.5 \%)$ followed by respect for clinicians and clients $(n=30,70.0 \%)$ and supervision $(n=24$, $55.8 \%)$. More than half found these organization activities to be very helpful $(n=23,53.5 \%)$ or somewhat helpful $(n=16$, $37.2 \%)$ in reducing stress. Personal activities were considered the most effective with majority $(n=26,61.9 \%)$ reporting these activities were very helpful in reducing stress. Leisure activities were the most highly endorsed personal stress reducers $(n=$ $40,93.0 \%)$ followed by making personal life a priority $(n=28$, $65.1 \%)$.

\section{Depression and PTSD}

The average score on the PCL-C was $27.1(S D=8.42)$ and on the CES-D was $9.6(S D=7.67)$. There was a significant correlation between CESD and PCL-C scores $r(34)=.49, p=$ .003 .

Mean PCL-C scores were significantly higher among women $(M=28.9, S D=8.7)$ than men $(M=23.5, S D=6.7), t(39)=$ $2.03, p=.049$. In addition, there was a significant correlation between higher CES-D scores and younger age, $r(34)=-.40$, $p=.019$.There was no difference in experiencing clinical levels of depression, $\chi^{2}(1, N=36)=3.39, p=.066$.

Linear multiple regression was used to examine the relationship between the independent variables and symptom variables. Age was significantly associated with depression scores, $\beta=$ $-.32, t(33)=-2.46, p=.019$; more work-related stress was
Table 2

Regression Analyses of PCL-C Scores With Gender, Traumatic Events, and Work Related Stress

\begin{tabular}{lrrrrrr}
\hline Variable & $B$ & $S E B$ & $\beta$ & $d f$ & $F$ & $p$ \\
\hline Step 1 & & & & 1 & 4.02 & .05 \\
$\quad$ Constant & 34.42 & 3.90 & & & & \\
$\quad$ Gender & -5.46 & 2.72 & -.31 & & & \\
Step 2 & & & & 2 & 1.96 & .16 \\
$\quad$ Constant & 32.28 & 5.32 & & & & \\
$\quad$ Gender & -4.74 & 3.00 & -.27 & & & \\
$\quad$ Life events & 0.08 & 0.13 & .10 & & & \\
Step 3 & & & & 3 & 3.36 & .03 \\
$\quad$ Constant & 39.74 & 6.13 & & & & \\
$\quad$ Gender & -3.94 & 2.89 & -.22 & & & \\
$\quad$ Life events & 0.04 & 0.13 & .05 & & & \\
$\quad$ Work stress & -3.69 & 1.70 & $-.33^{*}$ & & & \\
\hline
\end{tabular}

Note. $N=40 . \Delta R^{2}=.096$ for Step $1 ; \Delta R^{2}=.000$ for Step $2 ; \Delta R^{2}=.123$ for Step 3. PCL-C $=$ PTSD Checklist-Civilian Version.

${ }^{*} p<.05$.

related to higher scores on the PCL-C but not the CES-D. Work-related stress remained significant against PCL-C scores after gender and number of potentially traumatic events were included in the model (see Table 2).

\section{Discussion}

The findings of this study are consistent with research of human rights workers in similar positions reporting increased anxiety and depression (e.g., Holtz, Salama, Cardozo, \& Gotway, 2002). Although many providers in this pilot study reported that their work with victims of torture was stressful, they also indicated that their organizations prepared them for working with survivors of torture and had appropriate policies in place. Given these reports, it was striking that despite their organizations' efforts, many found personal activities to be the most effective ways to reduce their stress.

Although it appears that several programs within the NCTTP are working to develop a culture that recognizes the problems STS creates by signaling a commitment to service providers (e.g., diverse caseloads, comfortable work environment, peer support groups, and multiple resources for self-care), these steps vary from program to program. To reduce STS, prevent high turnover rates, and maintain emotional well-being among service providers, it is recommended that the NCTPP considers developing and adopting uniform guidelines for standards of provider self-care.

This small self-selected sample limits the ability to generalize findings to the larger population of professionals who care for survivors of torture. Professionals who may have experienced high levels of STS may have been less motivated to participate in the study to avoid emotionally laden issues. To increase 
generalizability, future research should consider outreach to the extensive network of refugee resettlement agencies as well as NCTTP members. Additionally, future recruitment strategies might consider outreach and data collection via web-based surveys.

Although these findings must be interpreted with caution, they offer useful information for approaches to clinical care. For professionals to competently address the needs of survivors of torture and human rights abuses, they also must be cared for.

\section{References}

American Psychiatric Association. (1994). Diagnostic and statistical manual of mental disorders (4th ed.). Arlington, VA: Author.

Blake, D. D., Weathers, F. W., Nagy, L. M., Kaloupek, D. G., Gusman, F. D., Charney, D. S., \& Keane, T. M. (1995). The development of a clinician-administered PTSD scale. Journal of Traumatic Stress, 8, 75-90. doi:10.1007/BF02105408

Blanch, A. (2008). Transcending violence: Emerging models for trauma healing in refugee communities. Alexandria, VA: National Center for Trauma Informed Care. Retrieved from http://annafoundation.org/ RefugeeTraumaPaperJuly212008.pdf

Eisenman, D. P., Gelberg, L., Liu, H., \& Shapiro, M. F. (2003). Mental health and health-related quality of life among adults living in the United States with previous exposure to political violence. Journal of the American Medical Association, 290, 627-634. doi:10.1001/jama.290.5.627

Fabri, M. R. (2001). Reconstructing safety: Adjustments to the therapeutic frame in the treatment of survivors of political torture. Professional Psychology: Research and Practice, 32, 452-457. doi:10.1037//0735-7028.32.5.452

Gerrity, E., Keane, T. M., \& Tuma, F. (2001). Introduction. In E. Gerrity, T. M. Keane, \& F. Tuma (Eds.), The mental health consequences of torture (pp. 3-12). New York: Plenum. doi:10.1007/978-1-4615-1295-0_1

Hanscom, K. L. (2001). Treating survivors of war trauma and torture. American Psychologist, 56, 1032-1039. doi:10.1037/0003-066X.56.11.1032b
Holtz, T. H., Salama, P., Cardozo, B. L., \& Gotway, C. A. (2002). Mental health status of human rights workers, Kosovo, June 2000. Journal of Traumatic Stress, 15, 389-395. doi:10.1023/A:1020133308188

International Rehabilitation Council for Torture Victims [IRCT], 2003. IRCT Annual Report 2003. Retrieved from http://www.irct.org/library/ irct_annual_reports.aspx.

Jenkins, S. R., \& Baird, S. (2002). Secondary traumatic stress and vicarious trauma: A validational study. Journal of Traumatic Stress, 15, 423-432. doi:10.1023/A:1020193526843

McDowell, I., \& Newell, C. (1996). Measuring health, a guide to rating scales and questionnaires (2nd ed.). New York: Oxford University Press.

Piwowarczyk, L., Moreno, A., \& Grodin, M. (2000). Health care of torture survivors. Journal of the American Medical Association, 284, 539-541. doi:10.1001/jama.284.5.539

Pope, K. S., \& Garcia-Peltoniemi, R. E. (1991). Responding to victims of torture: Clinical issues, professional responsibilities, and useful resources. Professional Psychology: Research and Practice, 22, 269-276. doi:10.1037//0735-7028.22.4.269

Radloff, L. S. (1977). The CES-D Scale: A self-report depression scale for research in the general population. Applied Psychological Measurement, 1, 385-401. doi:10.1177/014662167700100306

Silove, D. (1999). The psychosocial effects of torture, mass human rights violations, and refugee trauma: Toward an integrated conceptual framework. Journal of Nervous and Mental Disease, 187, 200-207. doi:10.1097/00005053199904000-00002

Walker, E. A., Newman, E., Dobie, D. J., Ciechanowski, P., \& Katon, W. (2002). Validation of the PTSD checklist in an HMO sample of women. General Hospital Psychiatry, 24, 375-380. doi:10.1016/S0163-8343(02)00203-7

Weathers, F., Litz, B., Huska, J., \& Keane, T. (1994). PTSD Checklist-Civilian Version. Boston, MA: National Center for PTSD, Behavioral Science Division.

Weathers, F., Litz, B., Herman, D., Huska, J., \& Keane, T. (1993, October). The PTSD Checklist (PCL): Reliability, validity, and diagnostic utility. Paper presented at the annual meeting of the International Society for Traumatic Stress Studies, San Antonio, TX.

Wenzel, T., Griengl, H., Stompe, T., Mirzaei, S., \& Kieffer, W. (2000). Psychological disorders in survivors of torture: Exhaustion, impairment and depression. Psychopathology, 33, 292-296. doi:10.1159/000029160 